\title{
Treatment of the steroid-resistant patient
}

\author{
RICHARD A KOZAREK, MD
}

RA KOZAREK MD. Treatment of the steroid-resistant patient. Can J Gastroenterol 1993;7(2):245-249. Although refractory inflammatory bowel disease (IBD) can be handled surgically or by nutritional supplementation or replacement in a subset of patients, immunosuppressive agents have gained widespread acceptance over the past several years. This is based upon a large number of uncontrolled and several controlled clinical trials demonstrating efficacy as well as the realization that side effects caused by immunosuppressive agents are dwarfed by those caused by long term, high-dose corticosteroids. Whereas 6 -mercaptopurine and azathioprine remain the drugs of choice based upon extensive clinical experience, both methotrexate and cyclosporin appear promising for otherwise refractory disease. The recent discovery of a Pglycoprotein efflux pump that promotes resistance to a large number of structurally related antineoplastic drugs, and recent attempts to inhibit induction of this pump, may have future implications for the use of immunosuppressive agents in IBD.

Key Words: 6-Mercaptopurinelazathioprine, Crohn's disease, Cyclosporin A, Immunosuppressive drugs, Inflammatory bowel disease, Methotrexate, Treatment/ therapy, Ulcerative colitis

\section{Traitement du patient réfractaire aux corticosteroïdes}

RÉSUMÉ: Bien que la maladie intestinale inflammatoire rebelle puisse être maîtrisée chirurgicalement ou par supplément ou remplacement nutritionnel, chez un sous-groupe de patients, les agents immunosuppresseurs ont gagné de plus en plus de popularité au cours des quelques dernières années. Cela est basé sur un grand nombre d'essais cliniques non contrôlés, et sur plusieurs essais contrôlés, qui en démontrent l'efficacité, de même que sur la réalisation que les effets secondaires causés par les agents immunosuppresseurs sont contrebalancés par ceux que provoquent les corticostéroïdes à dose élevée à long terme. Alors que la 6-mercaptopurine et l'azathioprine demeurent des médicaments de choix à cause de leur utilisation clinique répandue, le méthotrexate et la cyclosporine semblent prometteurs pour une maladie par ailleurs réfractaire. La découverte récente d'une pompe à efflux de glycoprotéine $\mathrm{P}$ qui favorise la résistance à un nombre de médicaments antinéoplasiques structuralement apparentés et les tentatives récentes d'inhiber l'induction de cette pompe pourraient avoir des implications à l'avenir sur le recours à des agents immunosuppresseurs dans la maladie intestinale inflammatoire.
Virginia Mason Clinic, Seattle, Washington, USA

Correspondence and reprints: Dr RA Kozarek, Virginia Mason Clinic, PO Box 900

(C3-N), Seattle, WA 98111 , USA. Telephone (206) 223-6934
T HeRAPEUTIC MANOEUVRES TO treat the steroid-resistant inflammatory bowel disease (IBD) patient include not only immunosuppressive drugs but also surgery and nutritional supplementation or replacement (Table 1). The latter includes caloric supplementation as well as elemental or formula diets together with home hyperalimentation. Surgery, in turn, can be directed against obstructive symptoms using segmental small bowel or colon resection, stricturoplasty or gastric bypass. Abscesses can be drained, fistulas in- or excised, and cures effected, at least in chronic ulcerative colitis with colectomy.

The use of immunosuppressive agents (Table 2 ) in the steroid-resistant IBD patient is presented here. Such therapy, while considerably less controversial today compared with 10 years ago, remains an art as opposed to a science. Not only is there an ongoing debate regarding which patient is a candidate for such medication, but also which disease process is suitable for this approach. As such, many clinicians have fewer qualms about its use in Crohn's disease than they do in chronic ulcerative colitis, a disease both surgically curable and with a significant penchant to develop dysplasia and subsequent colorectal carcinoma. Even after patient selection, additional questions abound. Which drug should be used? What are the clinical goals? How long should therapy continue? Does use entail enrollment in a clinical trial? 


\section{TABLE 1 \\ Treatment options for steroid-resis-
tant patients with inflammatory
bowel disease (IBD)}

Surgical

- Segmental resection/

stricturoplasty

- Gastric bypass

- Abscess drainage/

fistulectomy

- Colectomy

Alimentation

- Formula or elemental diet/ hyperalimentation

\section{Medication}

- Immunosuppressive drugs

\section{6-MERCAPTOPURINE/ AZATHIOPRINE}

6-mercaptopurine is an analog of the purine bases adenine and hypoxanthine and is converted to thioninosinic acid by the enzyme HGPRTase $(1,2)$. This acid ultimately inhibits purine ribonucleotide synthesis, thereby affecting inhibition of cellular turnover as well as immunosuppression. Whether such immunosuppression accounts for the anti-inflammatory effects noted with 6-mercaptopurine or azathioprine, an S-substituted 6-mercaptopurine cleaved to the parent molecule within the liver, is currently conjectural as both drugs also affect humoral responsiveness and selectively depress natural killer (NK) lymphocytic activity $(3,4)$. Moreover, recent studies suggest that clinical response to both drugs may be contingent upon induction of leukopenia, offering further support to drug efficacy as a consequence of immunosuppression $(5,6)$.

\section{CROHN'S DISEASE}

Two large, randomized, prospective trials have utilized immunosuppressive agents for refractory Crohn's disease. The National Cooperative Crohn's Disease Study (NCCDS) randomized patients with active disease into sevenweek treatment arms using prednisone, sulphasalazine, placebo and $25 \mathrm{mg} / \mathrm{kg}$ of azathioprine (7). While prednisone and sulphasalazine therapy proved useful for acute therapy, azathioprine did not appear to be statistically any better
TABLE 2

\section{Immunosuppressive drugs for the steroid-resistant IBD patient}

\begin{tabular}{ll} 
- & 6-Mercaptopurine/Azathioprine \\
- & Cycthotrexate \\
- & (FK-506) \\
- & (Corticosteroids) \\
- & ?(Sulphasalazine/5-ASA) \\
\hline
\end{tabular}

than placebo. Moreover, the significant incidence of drug associated pancreatitis ultimately led to withdrawal of azathioprine from the trial. In contrast, Present et al randomized 83 patients with Crohn's disease to either one year of 6-mercaptopurine or placebo therapy (8). Two-thirds of 6 mercaptopurine treated patients improved compared to only eight of the patients receiving placebo $(\mathrm{P}<0.0001)$.

Several recent uncontrolled series reinforce the use of immunosuppressive agents in Crohn's disease. O'Brien et al treated 78 patients with azathioprine for a mean of 1.6 years (9). Improvement was noted in 70 patients at a median response time of three months. Approximately three-quarters of patients achieved predefined therapeutic goals that included control of refractory disease (73\%), steroid-reduction (76\%) and improvement of fistulas $(63 \%)$. Ten percent of patients had side effects severe enough to require medication withdrawal, including three patients who developed serious infections and a fourth who developed pancreatitis. Sixteen instances of minor side effects were also noted, most commonly fever, myalgia, skin rash or headache. Mendelsohn et al successfully treated 162 of 230 Crohn's disease patients with 6-mercaptopurine for six months or longer (10). Therapeutic goals achieved included steroid elimination $(66 \%)$, healing of fistulas or abscesses $(66 \%)$ and a reduction in the Crohn's disease activity index (78\%).

Additional studies by Korelitz and Present have demonstrated a favorable effect of 6-mercaptopurine on Crohn's disease fistulae whereas Markowitz et al have demonstrated improvement in disease activity, decrease in steroid dosage and improvement in fistulous disease in 26 adolescents treated with 6-mercaptopurine for at least six months (12).

\section{CHRONIC ULCERATIVE COLITIS}

Recently published reports suggest that 6-mercaptopurine or azathioprine may also play a role in chronic ulcerative colitis despite concerns that prolonged treatment may be associated with subsequent increased risk of colorectal carcinoma. For instance, Adler and Korelitz reported the use of 6-mercaptopurine in 81 patients who received 91 courses of therapy for at least four months and a mean treatment time of 1.8 years (13). In approximately one half of treatment courses, steroids could be eliminated and $63 \%$ of patients ultimately responded. Follow-up data demonstrated a mean time of 21 months to relapse after medication discontinuation. Confirmatory data have been reported in abstract form by Present et al who noted that $43 \%$ of 56 steroid-resistant chronic ulcerative colitis patients experienced full remission and 30\% partial remission (14).

In contrast, Lobo et al described the use of azathioprine in 47 chronic ulcerative colitis patients with either severe, resistant disease or who had required steroids for control of disease activity for at least 12 months (15). Thirteen of 28 patients with resistant disease $(46 \%)$ achieved initial remission and 11 of 13 maintained this remission for a median of 22 months. Fifteen of the patients with refractory disease ultimately required colectomy. In the patients who had required continued high dose steroids for disease control, $63 \%$ had either reduction or withdrawal of corticosteroids. Side effects necessitating azathioprine cessation occurred in 26\% of patients and included hematologic effects in six patients, gastrointestinal effects in two patients and miscellaneous complications in an additional two patients. These latter results are significantly higher than the long term complication rates reported by Present et al (18) 
in 396 IBD patients treated with 6-mercaptopurine (pancreatitis 3.3\%, bone marrow depression $2 \%$, allergic reactions $2 \%$, drug related hepatitis $1 \%$ and possible medication related neoplasia $0.3 \%)$.

\section{METHOTREXATE}

Methotrexate, a folic acid antagonist, is an antimetabolite with significant immunosuppressant and antiinflammatory effects (17-20). Because of the latter, the drug has been widely used in psoriasis and various forms of arthritis (22-27). Moreover, it is currently undergoing investigation in asthma $(28,29)$, sclerosing cholangitis (30) and primary biliary cirrhosis (31). Because of its efficacy in a variety of inflammatory conditions, the present author began using the medication for refractory IBD in 1987. Using a 12 week course of $25 \mathrm{mg}$ methotrexate parenterally followed by a tapering oral dose, approximately three-quarters of 21 patients with refractory IBD went into remission as defined by steroid reduction or elimination and reduction in a disease activity index (32). Eleven of 14 Crohn's patients had a clinical response to methotrexate therapy and five patients with Crohn's colitis had endoscopic healing, four of whom had normal histology at 12 weeks. In contrast, none of the seven patients with chronic ulcerative colitis had normal flexible sigmoidoscopy at 12 weeks, although five had histologic improvement. Side effects included minor elevations in transaminase levels in two patients, transient leukopenia in one, nausea and self-limited diarrhea in two patients, and one case each of atypical pneumonia and brittle nails.

Additional studies from the author's institution have demonstrated that 16 of 20 IBD patients who developed either significant side effects (5), or proved refractory to at least six months of 6-mercaptopurine/azathioprine therapy (15), responded to a 12 week course of parenteral methotrexate (33). Twothirds of the initial responders maintained clinical remission for a mean of 71.5 weeks on subsequent oral methotrexate. Five patients ultimately required surgery, including three chronic ulcerative colitis patients colectomized for recurrent or refractory disease and two patients with Crohn's disease who underwent small bowel resection for obstructive disease. The authors concluded that previous failure to respond to 'conventional' immunosuppressants did not preclude acute or chronic response to methotrexate, although surgery was ultimately required in onefourth of treated patients. Data further suggested either differences in medication potency or mechanism of action.

More recent follow-up of IBD patients undergoing prolonged treatment with methotrexate suggests a significant discordance between chronic ulcerative colitis and Crohn's disease patients, with only $40 \%$ of the former patients remaining on the drug at 1.5 years and fully $50 \%$ electing or requiring ultimate colectomy (34). In contrast, two-thirds of the 30 patients with Crohn's disease who switched from parenteral to oral therapy remained on the drug and in remission at a mean follow-up of 69 weeks. Three patients died of unrelated causes, three relapsed and underwent subsequent surgical intervention, three had prolonged remission and discontinued the medication before an attempt at pregnancy, and one had the drug discontinued because of infectious pneumonitis. The authors concluded that long term results of chronic ulcerative colitis patients treated with methotrexate do not match those previously quoted for 6 mercaptopurine/azathioprine and that additional anti-inflammatory or immunosuppressive drugs should supplement or replace methotrexate in this setting.

Concerns about using methotrexate for refractory IBD are related both to lack of controlled trials as well as concerns regarding short and long term toxicity. Because of the dramatic clinical and endoscopic results in many IBD patients treated with methotrexate, the author's institution no longer considers it an investigational drug in this setting. Toxicity questions remain, however, and accordingly, its use is not recommended without a thorough informed consent. Side effects include variable degrees of leukopenia, post in- jection nausea, diarrhea or stomatitis, brittle nails, accentuated hair loss and transient elevations of liver function tests (32). Two toxicities deserve special mention: hypersensitivity pneumonitis and development of hepatic histologic abnormalities. The latter have been shown, at least in some series, to occur in up to a quarter of patients treated with long term methotrexate and to correlate not only with cumulative dose but also concomitant alcohol use (35). As such, it is recommended that alcohol should be avoided and liver biopsies are recommended at cumulative doses of 1.5, 3.0 and $5.0 \mathrm{~g}$ of methotrexate. No drug-induced histologic abnormalities have been noted by the author to date (36). The hypersensitivity pneumonitis, in turn, is an interstitial process associated with nonproductive cough, progressive shortness of breath and variable pulmonary infiltrates (37). It can be associated with progressive hypoxemia requiring intubation and while treated with high dose steroids and methotrexate cessation, deaths have occurred. As such, patients should be instructed to report ongoing pulmonary symptoms and to discontinue their weekly methotrexate until physician evaluation.

Finally, while methotrexate has the potential to induce fetal abnormalities, small series suggest that, although the incidence of spontaneous abortion may be higher, the incidence of congenital abnormalities is not (38). These data are similar to those reported with use of azathioprine in pregnancy (39). Nevertheless methotrexate should not be used in patients who do not practice birth control and should be stopped for six months in patients who are in remission and wish to become pregnant.

\section{CYCLOSPORIN A}

Cyclosporin has been used parenterally and orally in both Crohn's disease and chronic ulcerative colitis and has also been used rectally for refractory proctosigmoiditis (40-43). Similar rationale has led to the institution of clinical trials using the immunosuppressant FK-506 for refractory IBD. To date, no results are available. 


\section{MISCELLANEOUS}

Immunosuppressive activity has not only been noted with steroids which affect the inflammatory cascade at multiple levels, but also variably used drugs including metronidazole and the antimalarials (44-46). In addition, recent data also suggest that sulphasalazine has immunomodulation properties that may mediate a portion of its clinical efficacy. For instance, in a doubleblind, randomized, crossover trial utilizing either sulphasalazine or 5-aminosalicylic acid (5-ASA) in five IBD patients in remission and four healthy volunteers, natural killer cell activity was significantly impaired in two-thirds of the sulphasalazine-treated patients (46). This appeared to be related to the sulphapyridine moiety as there was litthe effect on the lymphocytes of patients undergoing 5-ASA treatment. Finally, T-lymphocyte apheresis, used anecdotally in 65 Crohn's disease patients in an attempt to induce remission, seems to be the ultimate form of immunosuppression, and has proven beneficial in a subset of refractory patients $(48,49)$.

\section{REFERENCES}

1. Elion GB. Biochemistry and pharmacology of purine analogues. Fed Proc 1967;26:898-904.

2. Adler DJ, Korelitz BI.

6-mercaptopurine and azathioprine. In: Gitnick, G. ed. Inflammatory Bowel Disease. Diagnosis and Treatment. New York, Igaku-Shoin, 1991;323-46.

3. Brogan M, Stevens R, Histerodt J, et al. Effects of 6-MP on the impaired in vivo humoral responsiveness in Crohn's disease. Gastroenterology 1984;86:1035A.

4. Brogan M, Histerodt J, Stevens, et al. The effects of 6-mercaptopurine on the natural killer cell activities in Crohn's disease. J Clin Immunol 1985;5:204.

5. Burke DA, Dixon MF, Axon ATR. Ulcerative colitis: prolonged remission following azathioprine-induced pancytopenia. J Clin Gastroenterol 1989;11:327-30.

6. Colonna T, Korelitz BI. The role of leukopenia in the 6-mercaptopurine induced remission of Crohn's disease. Am J Gastroenterol 1991;86:1345A.

7. Summers RW, Switz DM, Sessions JT, $\mathrm{Jr}$, et al. National Cooperative Crohn's Disease Study: Results of drug

\section{CONCLUSIONS}

Treatment of the steroid-resistant IBD patient involves multiple strategies including surgery, nutritional supplementation or replacement, psychologi$\mathrm{cal}$ and psychosocial support and immunosuppressive drugs. 6-mercaptopurine/azathioprine have undergone the closest scrutiny, having been used for prolonged periods in large numbers of patients, and remain the drugs of choice if immunosuppressive agents are used. Both methotrexate and Cyclosporin A appear promising for refractory IBD, particularly Crohn's disease. Additional data to include long term toxicity profiles are needed before widespread application of either.

What of the future? The discovery of the efflux pump that promotes resistance to a large number of structurally unrelated cancer drugs has been heralded as 'the most important research accomplishment in antineoplastic pharmacology during the past decade' (50). The induction of P-170 glycoprotein helps to explain why initial tumour sensitivity to multiple antineoplastic compounds is rapidly lost and suggests that blocking such induc-

treatment. Gastroenterology 1979;77:847-69.

8. Present DH, Korelitz BI, Wisch N, Glass JL, Sachar DB, Pasternack BS. Treatment of Crohn's disease with 6-mercaptopurine. A long term, randomized, double blind study. N Engl J Med 1980;302:981-87.

9. O'Brein JJ, Bayless TM, Bayless JA. Use of azathioprine or 6-mercaptopurine in the treatment of Crohn's disease. Gastroenterology 1991;101:39-46.

10. Mendelsohn RA, Adler DJ, Korelitz BI. The long term efficacy of 6-mercaptopurine in the treatment of Crohn's disease; an update. Am J Gastroenterol 1991;86:1347A.

11. Korelitz BI, Present DH. Favorable effects of 6-mercaptopurine on fistulae of Crohn's disease. Dig Dis Sci 1985;30:58-64.

12. Markowitz J, Rosa J, Grancher K, Aiges H, Daum F. Long term 6-mercaptopurine treatment in adolescents with Crohn's disease. Gastroenterology 1990;99:1347-51.

13. Adler DJ, Korelitz BI. The therapeutic efficacy of 6-mercaptopurine in refractory ulcerative colitis. Am J tion might provide sustained tumoricidal activity in patients undergoing chemotherapy (51-53). Verapamil, tamoxifin, quinidine, cyclosporin A and monoclonal antibodies to P-170 have all been shown in vitro or in vivo to impair development of P-glycoprotein and may clinically prove helpful in overcoming multidrug resistance $(52,53)$. This development should not be lost on the gastroenterologic community as similar development of drug resistance or tolerance is a common clinical problem, not only with immunosuppressive agents but also with more conventional anti-inflammatory agents. One possible future scenario includes multiple drug therapy in patients with refractory IBD disease, each medication attacking various aspects of the inflammatory or immunologic cascade, and the subsequent use of a compound that prevents the development of resistance to these various drugs. In the absence of specific 'cures' being developed, IBD drug therapy for the steroid-resistant patient may therefore be comparable to the patient approach used in oncology and, increasingly, in other disciplines such as rheumatology.

Gastroenterol 1990;85:717-22.

14. Present DH, Chapman ML, Rubin PH. Efficacy of 6-mercaptopurine in refractory ulcerative colitis. Gastroenterology 1988;94:359A

15. Lobo AJ, Foster PN, Burke DA, Johnston D, Axon AT. The role of azathioprine in the management of ulcerative colitis. Dis Colon Rectum 1990;33:374-7.

16. Present DH, Meltzer Si, Krumholz MP, Wolke A, Korelitz BI. 6-mercaptopurine in the management of inflammatory bowel disease: Shortand long-term toxicity. Ann Intern Med 1989;111:641-9.

17. Segal R, Mozes E, Yaron M, Tartakovsky B. The effects of methotrexate on the production activity of interleukin-1. Arth Rheum 1989;32:370-7.

18. Calabrese LH, Taylor JV, Wilke WS, et al. Response of immunoregulatory lymphocyte subsets to methotrexate in rheumatoid arthritis. Cleve Clin J Med 1990;57:232-41

19. Miller LC, Cohen SE, Orencole SF, et al. Interleukin-1 is structurally related to dihydrofolate reductase: effect of methotrexate on IL-1. 
Lymphokine Res 1988;7:272A.

20. Mitchell LC, Turk JL. Effect of the immune modulating agents cyclophosphamide, methotrexate, hydrocortisone, and cyclosporin A on an animal model of granulomatous bowel disease. Gut 1990;31:674-8.

21. Olsen NJ, Murray LM.

Antiproliferative effects of methotrexate on peripheral blood mononuclear cells. Arth Rheum 1989;32:378-85.

22. Christophidis N. Methotrexate. Clin Rheum Dis 1984;10: 401-15.

23. Lanse SB, Arnold GL, Gowans JDC, Kaplan MM. Low incidence of hepatotoxicity associated with long-term, low-dose oral methotrexate in treatment of refractory psoriasis, psoriatic arthritis, and rheumatoid arthritis. An acceptable risk/benefit ratio. Dig Dis Sci 1985;30:104-9.

24. Healey LA. The current status in methotrexate use in rheumatoid diseases. Bull Rheum Dis 1986;36:1-10.

25. Williams HJ, Willkens RF, Samuelson $\mathrm{CO}$, et al. Comparison of low-dose oral pulse methotrexate and placebo in the treatment of rheumatoid arthritis. A controlled clinical trial. Arthritis Rheum 1985;28:721-30.

26. Andersen PA, West SG, O'Dell JR, Via CS, Claypool RG, Kotzin BL. Weekly pulse methotrexate in rheumatoid arthritis. Clinical and immunologic effects in a randomized, double-blind study. Ann Intern Med 1985; 103:489-96.

27. Lally EV, Ho G, Jr. A review of methotrexate therapy in Reiter syndrome. Semin Arthritis Rheum 1985;15:139-45.

28. Mullarkey MF, Webb DR, Pardee NE. Methotrexate in the treatment of steroid-dependent asthma. Ann Allergy 1986;56:347-50.

29. Mullarkey MF, Blumenstein BA, Andrade WP, Baily GA, Olason I, Wetzel E. Methotrexate in the treatment of corticosteroid-dependent asthma. A double-blind cross-over study. N Engl J Med 1988;318:603-7.

30. Knox TA, Kaplan MM. Treatment of primary sclerosing cholangitis with oral methotrexate. Am J Gastroenterol 1991;86:546-52.

31. Kaplan MM, Knox TA, Arora S.
Primary biliary cirrhosis treated with low-dose oral pulse methotrexate. Ann Intern Med 1988;109:429-31.

32. Kozarek RA, Patterson DJ, Gelfand MD, Botoman VA, Ball TJ, Wilskek $\mathrm{R}$. Methotrexate induces clinical and histologic remission in patients with refractory inflammatory bowel disease. Ann Intern Med 1989;110:353-6.

33. Kozarek RA, Patterson DJ, Botoman VA, et al. Methotrexate use in inflammatory bowel disease patients who have failed azathioprine or 6-mercaptopurine. Gastroenterology 1991;100:222A.

34. Kozarek RA, Patterson DJ, Gelfand $\mathrm{MD}$, et al. Long-term use of methotrexate in inflammatory bowel disease. Gastroenterology 1992;102:648A.

35. Whiting-O'Keefe QE, Fye KH, Sack KD. Methotrexate and histologic abnormalities: a meta-analysis. Am J Med 1990;90:711-6.

36. Kozarek RA, Bredfeldt JE, Rosoff LE, Patterson DJ, Fenster LF. Does chronic methotrexate cause liver toxicity when used for refractory inflammatory bowel disease? Gastroenterology 1991; 100:221A.

37. Searles G, McKendry RJR. Methotrexate pneumonitis in rheumatoid arthritis: potential risk factors. Four case reports and a review of the literature. J Rheumatol 1987;14: 1164-71.

38. Kozlowski RD, Steinbrunner JV, MacKenzie AH, Clough JD, Wilke WS, Segal AM. Outcome of first-trimester exposure to low-dose methotrexate in eight patients with rheumatic disease. Am J Med 1990;88:589-92.

39. Alstead EM, Ritchie JK, Lennard-Jones JE, Forthing MJ, Clark ML. Safety of azathioprine in pregnancy in inflammatory bowel disease. Gastroenterology 1990;90:443-6.

40. Hodgson HJF. Cyclosporin in inflammatory bowel disease. Aliment Pharmacol Therap 1991;5:343-50.

41. Lowes JR, Jewell DP. Cyclosporin A in inflammatory bowel disease. Gitnick G, ed. In: Inflammatory Bowel Disease. Diagnosis and Treatment. New York, Igaku-Shoin: 1991;359-64.
42. Brynskov J, Freund L, Rasmussen SN, et al. A placebo-controlled, double-blind, randomized trial of cyclosporine therapy in active Crohn's disease. N Engl J Med 1989;321:845-50.

43. Lichtiger S, Present DH. Preliminary report: cyclosporin in treatment of severe active ulcerative colitis. Lancet 1990;i:16-9.

44. Hawthorne AB, Hawkey C]. Immunosuppressive drugs in inflammatory bowel disease. A review of their mechanisms of efficacy and place in therapy. Drugs 1989:38:267-88.

45. Hanauer SB, Stathopoulos G. Risk-benefit assessment of drugs used in the treatment of inflammatory bowel disease. Drug Safety 1991;6:192-219.

46. Freeman HJ. Immunosuppressive drug therapy of inflammatory bowel disease. Endosc Rev 1991;8:26-31

47. Aparico-Pagies MN, Verspaget HW, Hafkenscheid JC, et al. Inhibition of cell mediated cytotoxicity by sulphasalazine: effect of in vivo treatment with 5-aminosalicylic acid and sulphasalazine on in vitro natural killer cell activity. Gut 1990;31:1030-2

48. Bicks RO, Groshart KD. The current status of T-lymphocyte apheresis (TLA) treatment of Crohn's disease. J Clin Gastroenterol 1989;11:136-8.

49. Bicks RO, Groshort KD.

T-lymphocyte apheresis. In: Gitnick G, ed. Inflammatory Bowel Disease. Diagnosis and Treatment. New York: Igaku-Shoin, 1991:377-95.

50. Chabner BA, Wilson W. Reversal of multidrug resistance. J Clin Oncol 1991;9:4-6. (Edit)

51. Goldstein LJ, Ozols RF. Blocking P-glycoprotein action. Contemp Onc 1991;May/June:38-47.

52. Pastan I, Willingham MC, Gottesman M. Molecular manipulations of the multidrug transporter: a new role for transgenic mice. FASEB ] 1991;5:2523-8

53. Lehnert M, Dalton WS, Roe D, Emerson S, Salmon SE. Synergistic inhibition by verapamil and quinine of p-glycoprotein-mediated multidrug resistance in a human myeloma cell line model. Blood 1991;77:348-54. 


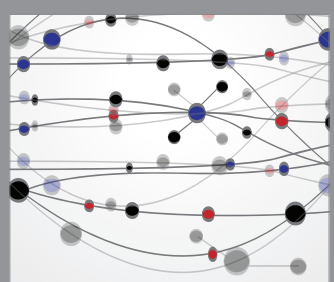

The Scientific World Journal
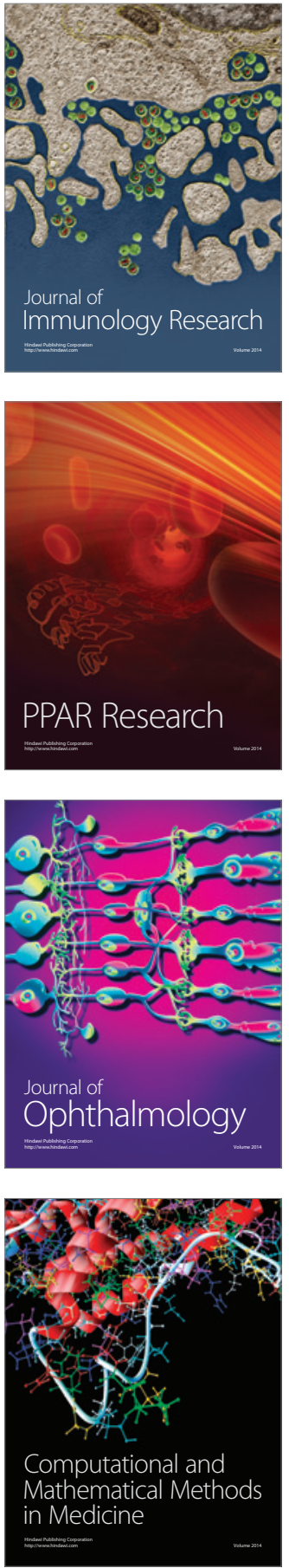

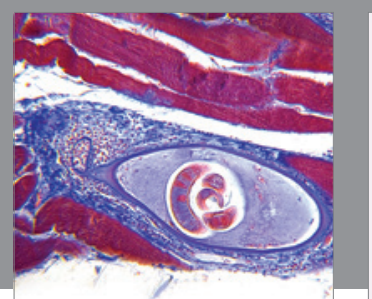

Gastroenterology Research and Practice

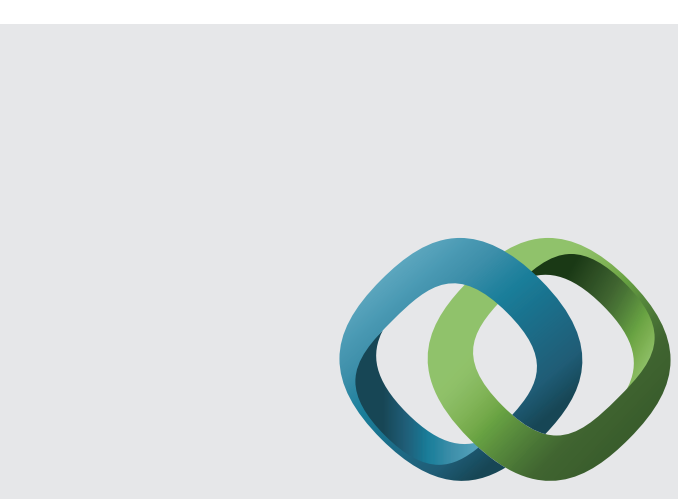

\section{Hindawi}

Submit your manuscripts at

http://www.hindawi.com
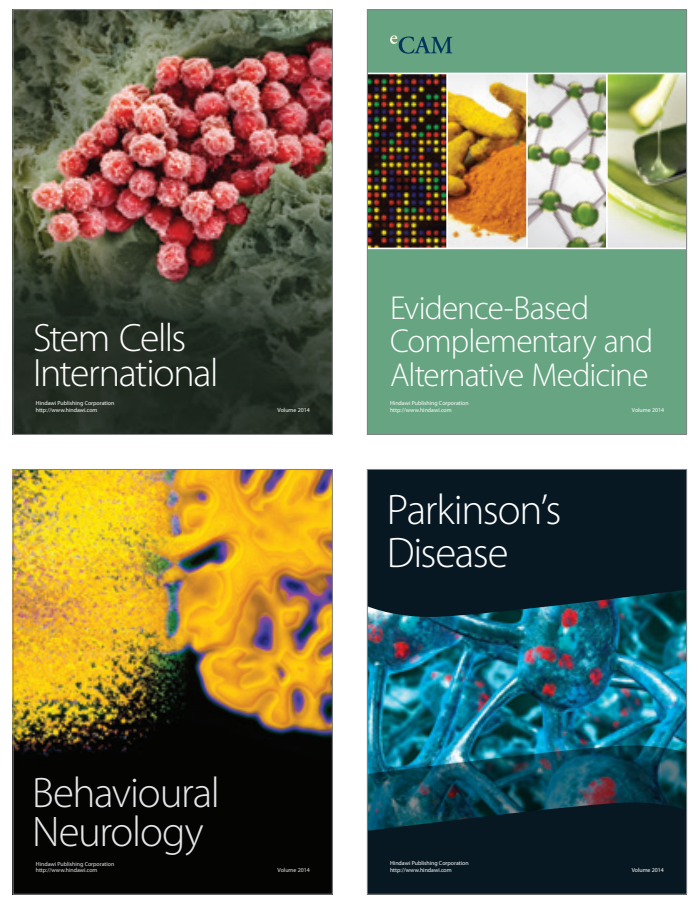
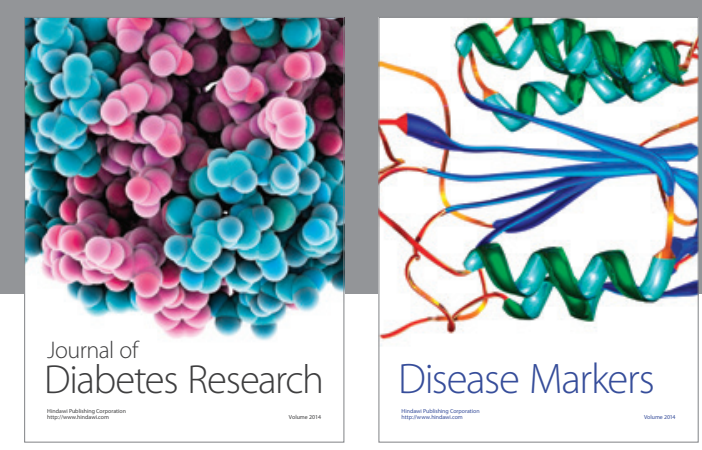

Disease Markers
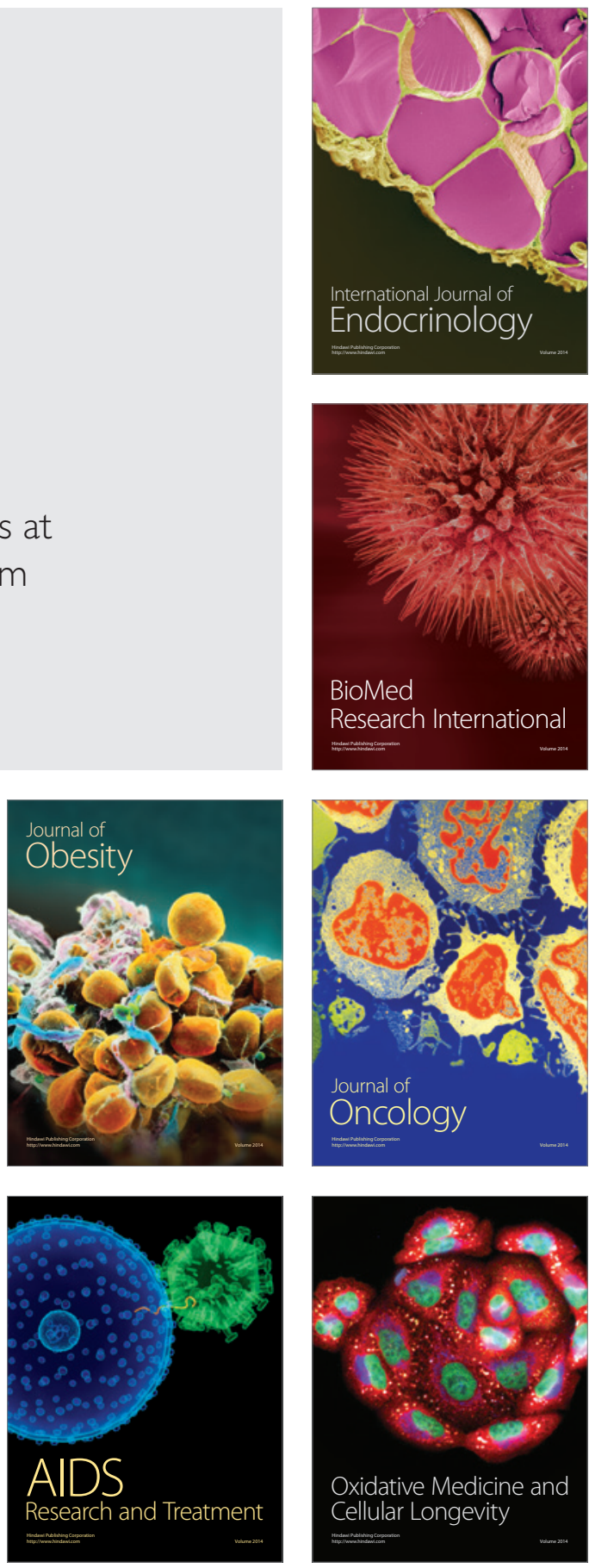